\title{
Error Analysis of Students' Sentence Structure in Writing Application Letter
}

\author{
Rika Arista $^{1}$, Dewi yana ${ }^{2}$, Sri Sugiharti ${ }^{3}$ \\ English Department \\ University of Riau Kepulauan \\ arista.rika@gmail.com ${ }^{1}$, alifdewi@yahoo.com ${ }^{2}$, srisugihartiwismono@yahoo.com ${ }^{3}$
}

\begin{abstract}
This research was aimed to describe the kind of the classification and the dominant of error that made by the student in writing application letter at the twelfth grade of SMKN 5 Batam in the academic year 2015/2016. The analysis of error in the foreign language learning was important to help the teacher to take an immediate action to avoid the re-occurrence of error. This study was limited only in the classification of error in the element of sentence and the application letter format. The research was conducted in April 2016 and was held on twelfth grade with the number of sample was 50 students. Data was collected by the written test and analyzed by descriptive method to describe the students' error. The result of the research presented there was 1188 errors in the application letter format and sentence structure in writing application letter. There were $45.03 \%$ with number 535 errors of omission, $14.06 \%$ with number 167 errors of addition, $36.03 \%$ with number 428 errors of selection, and $4.88 \%$ with number 58 errors of ordering. The dominant sentence structure error was $7.15 \%$ with number 85 errors of omission in the adverbial and adverbial complement element of the simple sentence. A lot of error in the element of the sentence structure in writing application letter caused by the omission, selection, and addition of some letter in the element. The error also caused by the application of the capital letter, punctuation, and conjunction while the error of ordering was due to the sequence of the element in the sentence structure was incorrect placed. Based on the finding of the research, the researcher suggested that the teacher should pay more attention in the writing subject learning and correct the error directly to avoid the re-occurrence of the error, while for the school should facilitate the overall English teaching.
\end{abstract}

Keywords: error analysis and sentence structure

\section{INTRODUCTION}

The objective of the study was to identify the classification and the dominant of errors in sentence structure made by the student at twelfth grade of SMKN 5 Batam in the Academic Year 2015/2016 in writing application letter. Application letter was one of the important businesses writing that had been studied. It was due to in any getting job, the applicants had to submit application letter to show their qualification prolife to the user whose would use their services. But in foreign language learning, making error was common. It was due to that the foreign and mother language had different structure in the building a sentence. Students usually 
ignored the use of some element that they though it was not really important. Maxom (2009:211), around the world there are thousands of languages, each with its own grammatical system. This meant that the students could easily get wrong when they tried to put words together to make a sentence in English. Error that was happen in this learning had been investigated by identify and classify the error as the first step to understand the source of error. The investigation was important. It could help the teacher to take immediate action to avoid the reoccurrence of error especially in writing application letter at this twelfth grade and for the future class.

There were two identifications of the study. The first was the students got difficulty in building sentence based on the correct sentence structure such as the use of punctuation, identify part of speech, and identify the function of the words in sentence. The second one was the students had problem in writing letter, especially application letter. The study was limited only in the classification of error of omission, addition, selection, and ordering in the simple, compound, and complex sentence structures then for application letter only in the structure and format in writing application letter at the twelfth grade of SMKN 5 Batam.

\section{Error Analysis}

According to Lennon (cited in Brown, 2000) in Amara (2015:59), an error is a linguistic form or combination of form which, in the same context and under the same context and under similar conditions of production, would, in all likelihood, not be produced by the speakers' native speaker counterparts, while Abushihab (2014:214) defined that errors occur repeatedly and cannot be recognized by the learner. Hence, only the teacher or researcher could locate them.

There were differences between error and mistake. Mistake can be done due to inconsistency and can be self-corrected while error is systematic problems happen due to incompetence the foreign language learner in learning target language. It is affected by their habits in using of mother language. The errors cannot be self-corrected by learner. It needs teacher and researcher to locate the error for immediate action to avoid the reoccurrence of error. The error can be observed, analyzed and classified to know the learners' errors. Mourtaga (2004) in Abushihab (2014:214), also said points out the errors and mistakes are different from each other because an error cannot be self-corrected and is caused by a learners' inadequate knowledge of the target language whereas mistake can be self-corrected. Another definition came from Brown (2000) in (Xue-mei and Fang, 2007:11) a "mistake" refers to a performance error in that it is a failure to utilize a known system correctly, while an "error" is a noticeable 
deviation from the adult grammar of a native speaker, reflecting the inter-language competence of the learner.

Error analysis is analyzing the deviations made by the language learner. It can be done by classify the deviations. It tried to investigate how far the language learner understands the target language. Al-Badawi (2012:536) mentioned that error analysis is an applied linguistics approach used to identify areas of great difficulty for second language learners. Brown (2000) in Amara (2015:60) defined that error analysis as the process to observe, analyze, and classify the deviations of the rules of the second language and then to reveal the systems operated by learner.

The error could be classified to omission, addition, and ordering. Corder (1973) in Erdogan (2005:263:264) classified the error in terms of the difference between the learners' utterance and reconstructed version. In this way, errors fall into four categories: omission of some required element; addition of some unnecessary or incorrect element; selection of an incorrect element; and miss-ordering of the elements. The omission is the happen where some element is omitted which should be present, for example '*Arya want to meet his friend'. The omission of element "s" in element want as a predicate or verb is incorrect. It should be wants, because the subject of this sentence is third person singular. It followed by verb or predicate with "-s/-es" in present tense in active voice which has pattern $\mathrm{S}+\mathrm{V} 1(-\mathrm{s} /$-es $)+$ (O/Complement) / adverbial (Dutwin 2010:33). The correct sentence is 'Arya wants to meet his friend'. The addition is happen where some element is present which should not be there, for example "*I sings a song'. The addition of element "-s" in sing as a predicate or verb is incorrect. It should be sing, because in the Present tense in active voice which has pattern $\mathrm{S}+$ $\mathrm{V} 1(-\mathrm{s} /$-es $)+(\mathrm{O} /$ complement $) /$ Adverbial and the subject "I" is followed by the verb without “-s/-es" (Dutwin 2010:33), so it should be sing. The correct sentence is 'I sing a song'. The selection is happen where the wrong item has been chosen in place of the right one, for example “*Nuri eat noodle yesterday'. The selection of element "eat" as a verb or predicate is incorrect. It should be ate, because the adverb of time yesterday, it means the tense is past tense in active voice which has pattern $\mathrm{S}+\mathrm{V} 2+(\mathrm{O} / \mathrm{Complement}) /$ Adverbial (Dutwin 2010:18,33), so the correct sentence is 'Nuri ate noddle yesterday'. The ordering is happen where the elements presented are correct but wrongly sequenced, for example '*We have been $\underline{\text { not }}$ meeting you'. The sequence of "not" should be after have and before been. It is present prefect tense in negative sentence which has pattern $\mathrm{S}+$ Have/has + not + been $+\mathrm{V} 3+\mathrm{O} /$ Complement (Dutwin 2010: 18,52), so the correct sentence is 'We have not been meeting you'. 


\section{Sentence Structure}

The sentence expresses a complete though. It is the large unit of combining word. It can be a single or multiple clauses. Leech (2006:104) in Alduais (2012:207) defined that sentence is the largest unit of language that it is the business of grammar to describe. The sentences are marked by beginning with capital letter and ending with a full stop (.), question mark (?), or exclamation mark (!). Greenbaum and Nelson (2002:23-32), the elements of the sentence are subject, verb, object, complement, and adverbial. The subject element is a noun phrase, the verb element is verb phrase, the object element is a noun phrase, the complement can be an adjective phrase and a noun phrase, and the adverbial can be adverb phrase, prepositional phrase, and noun phrase. Greenbaum and Nelson (2002:20-37), mentioned that Sentence structure is formed by an element. The elements of sentence structure have meaning such as Subject, verb, object, complement and adverbial. Each element of sentence structure can be a phrase. A sentence can be structured by one or more clauses

According to Dutwin (2010:172-185), kind of sentences are a simple sentence, compound sentence, complex sentence and compound-complex sentence while Greenbaum and Nelson (2002:20-37), mentioned that the kind sentence are simple, compound, and complex sentence. The simple sentence consists only one independent clause for example, 'Visualization prepares athletes for success.' (Dutwin 2010:172). Compound sentences have two main clauses, each with independent status. Structure can be analyzed in term of sentence elements such as subject and predicate. It is consisted two or more coordinate clauses are normally linked by one of the coordinating conjunctions (and, or, but) for example, 'Visualization (I) and (cc) practice prepare athletes for success (I)'(Dutwin 2010:175). Complex sentence is a multiple sentence in which one or more subordinate clauses are embedded. They are connected by subordinate conjunction for example, 'because it is sunny today (D), we don't have raincoats in the car (I)'(Dutwin 2010:181).

\section{Application Letter}

Application letter is one kind of the formal letter. Field (2009:136) in writing formal letter, the same rules apply as in personal letter but this one will, if possible, be typed and there are other rule. Application letter was important as the first step to get any job. Applicant used application letter to perform their qualification of profile. That's way applicant had to write an interest and simplify application letter to give the right impression. In another definition Widiati et al (2015:34-41) explained that application letter is one of the important letter in the English subject especially for vocational high school. Application letter was written usually to 
apply for employment. According to Wilson \& Wauson (2010:454-458), there were several different format for business letters, block letters, modified block letter, modified semi block letter, and simplified letters. The structure of application letter was explained in the seventh structures. They were:

a) Applicant Address. The application letter should indicate the applicant address.

b) Date. The applicant should write the date when the application letter was written.

c) Company Address. The applicant should write address of the company that applicant writing to. It should use complete title and address; should not an abbreviation.

d) Greeting. The applicant should write always make an effort to write directly to the person in charge of hiring.

e) Opening paragraph. This paragraph was to specify which job that applicant applying for, or, if they were writing to inquire whether a job position was open, question the availability of an opening.

f) Middle paragraph(s)/body. This paragraph should be used to highlight the applicant work experience which most closely matches the desired job requirements presented in the job opening advertisement. Should not simply restate what was contained in applicant resume, but give strong reasons why applicants are suited to the position.

g) Closing paragraph. This closing paragraph was to ensure action on the part of the reader. One possibility was to ask for an interview appointment time. Make it easy for the personnel department to contact applicant by providing applicant telephone number and email address.

h) Finishing letter. The finishing in the application letter could be thanks and sign.

\section{METHODOLOGY}

This research was conducted in the SMKN 5 Batam in 5 to 23 April 2016. The subject of the study was the twelfth grade of SMKN 5 Batam in the academic year 2015/2016. The researcher used simple random sampling because all of the students at the twelfth grade of this school had gotten same material in English. The sample was 50 participants. This was $18 \%$ of the total population with number 284 students as Given (2008:102) said that some qualitative methods, such as phenomenological approaches, do not aim at finding common patterns but want to find the underlying structure or essence via an intensive descriptive study of individual cases, Give (2008:124) also mentioned a convenience sample can be described as a group of participants who have been recruited for a given study because they were readily accessible. 
The technique of collecting data used primary data in specific test. It was written test to collect data by asking the sample to write application letter, Lundy in Give (2008:396) Primary sources refer to first-person accounts of events in original documents, letters, artwork, literature, music, observational notes, journals, and photographs. Primary sources enable the researcher to get as close as possible to what actually happened during a historical event

The data was or time period. Garnham in Give (2008:192) also explained data source in the qualitative research can be human participants, documents, organizations, electronic media, and events. analyzed by using descriptive design, Hoonaard in Give (2008:186-188) said data analysis is an integral part of qualitative research and constitutes an essential steppingstone toward both gathering data and linking one's findings with higher order concepts. There were processing raw data and analyzed the result of processing the raw data. In the processing of the raw data, there were editing, coding, classification, tabulation, and using percentage with the following formula:

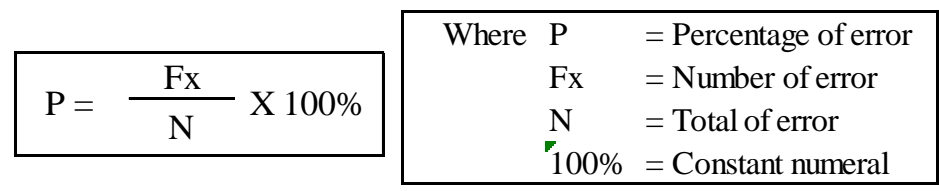

The final of analyzing data was interpreting. Firstly the researcher explained and interpreted how generalization should be done and concepts be formulated. Secondly, the researcher considered the extraneous information. It proved to be a key factor in understanding the problem under consideration. Thirdly, the researcher asked suggestion and consulted with advisor that involved in this study to get correct interpretation, thus, will enhance the utility of research results. Finally, the researcher accomplished the task interpretation only after considering all relevant factors affecting the problem to avoid false generalization.

\section{RESULTS}

There were found 1188 errors that made by student in both application letter format and sentence structure. There were $45.03 \%$ error of omission, $3.45 \%$ error of addition, $36.03 \%$ error of selection, and $4.88 \%$ error of ordering. 


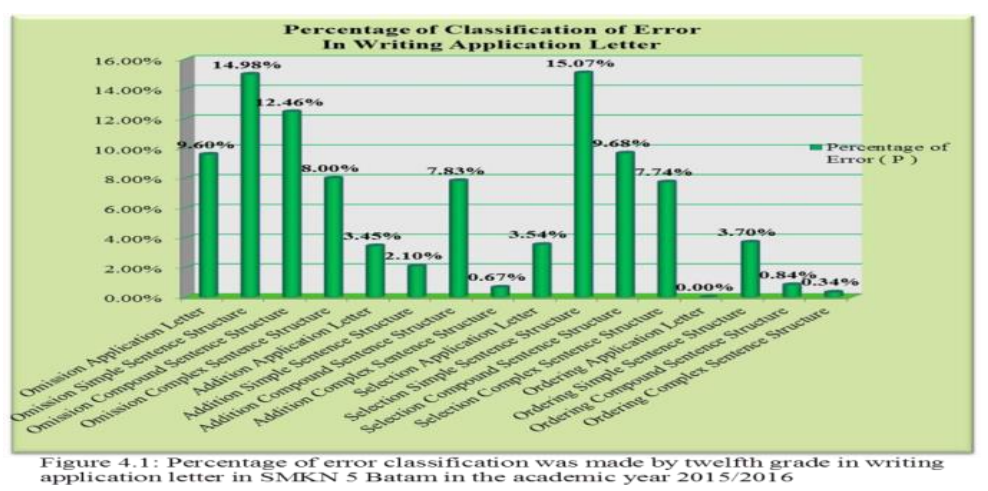

There were $45.03 \%$ with number 535 errors of omission. They were $9.60 \%$ error of omission in the application letter format, $8.00 \%$ error of omission in the complex sentence structure, $12.46 \%$ error of omission in the compound sentence structure, and $14.98 \%$ error of omission in the simple sentence structure. There were $14.06 \%$ with number 167 errors of addition.

They were $3.45 \%$ with number 41 errors of addition in the application format, $0.67 \%$ with number 8 errors of addition in the complex sentence structure, $7.83 \%$ with number 93 errors of addition in the compound sentence structure, and $2.10 \%$ with number 25 errors of addition in the simple sentence structure.

There were $36.03 \%$ with number 428 errors of selection. They were $3.54 \%$ with number 42 errors of selection in the application letter format, 7.74\% with number 92 errors of selection in the complex sentence structure, $9.68 \%$ with number 115 errors of selection in the compound sentence structure, $15.07 \%$ with number 179 errors of selection in the simple sentence structure.

There were $4.88 \%$ with number 58 errors of ordering. They were $0.34 \%$ with 4 errors of ordering in the complex sentence structure, $0.84 \%$ with number 10 errors of ordering in the compound sentence structure, $3.70 \%$ with number 44 errors of ordering in the simple sentence structure.

\section{DISCUSSION}

Below was the discussion of the dominant error of sentence structure and application letter format made by the twelfth student of SMKN 5 Batam in the academic years 2015/2016 in writing application letter.

\section{The error of selection of the simple sentence structure}


The sentence '*I am looking Forward to hearing From you' should be 'I am looking forward to hear from you'.

The letter ' $\mathrm{f}$ ' in the verb 'Forward' and in the adverbial complement should not be capital because the letter is not the beginning of the sentence and the element is verb (Dutwin 2010:116). The object of 'to hearing' should be 'to hear' because the form of the object used to infinitive which had form 'to + V1' instead of 'to + Ving' (Gelderen 2010:150).

\section{The error of omission and selection in the simple sentence structure}

The sentence '*I shall highly appreciats an opportunity to explain myexperience to you in Person during my Interview' should be 'I shall highly appreciate an opportunity to explain my experience to you in personal during my interview.'

The verb 'apreciats' should be 'appreciate' there was wrong selection in letter. The complement 'myexperience' should be 'my experience' it should have space. The letter 'p' and 'I' in adverbial complement 'Person and Interview' should not be capital (Dutwin 2010:116). The adverbial "in person" should be "in personal", the word "person" was omitted "al". The "person" is noun and "personal" is adjective. The adverbial form in the sentence was built from an adjective phrase. The main word in the adjective phrase is an adjective. (Greenbaum and Nelson 2002:268).

\section{The error of omission, addition and selection of compound sentence structure}

The sentence '*I Have given bellow in brief my Qualification and experience For your kind consideration' should be 'I have given below in brief my qualification and experience for your kind considerations.'

The letter ' $\mathrm{H}$ ' in the verb 'Have', the letter ' $\mathrm{Q}$ ' in the adverbial complement 'Qualification' and letter 'F' in the 'For' should not be capital (Dutwin 2010:116). The letter ' 1 ' in the object complement 'bellow' was typed double. The adverbial 'consideration' was omitted letter 's'. The word 'consideration' should be plural because it explained two words. They are 'qualification' and ‘experience' (Dutwin 2010:12).

\section{The error of omission in application letter format}

In the student authentic application letter, there was no subject in the application letter. In the semi modified block letter format, the applicant should write the subject which mentioned the vacant position (Wilson \& Wauson, 2010:457). 


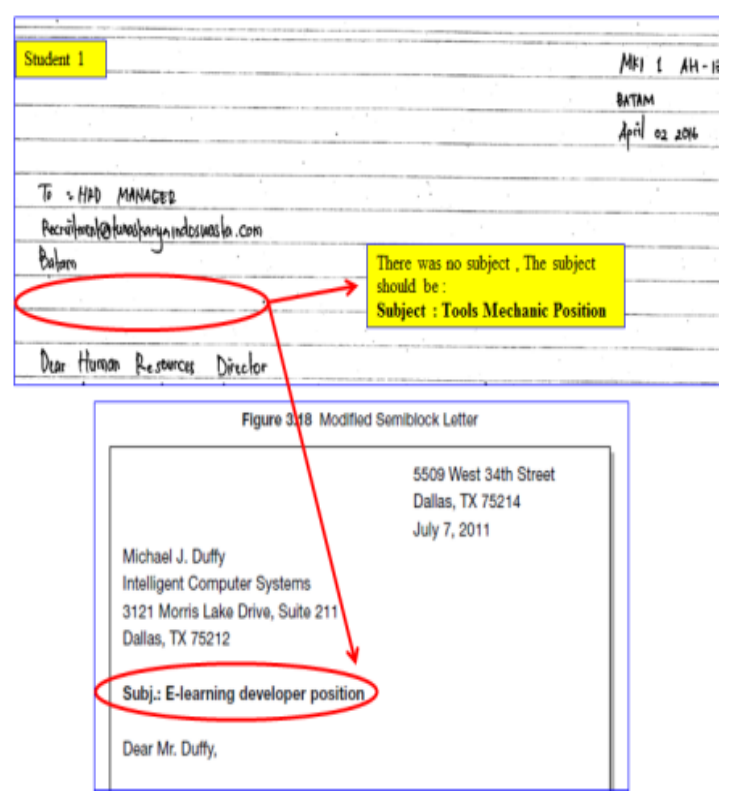

The analysis of the data presented 1188 errors in the sentence structure and application letter format error that made by the twelfth grade of SMKN 5 Batam in the academic year 2015/2016 in writing application letter. the kind of classification of error in sentence structure in writing application letter were $45.03 \%$ with number 535 errors of omission, $14.06 \%$ with number 167 errors of addition, $36.03 \%$ with number 428 errors of selection, and $4.88 \%$ with number 58 errors of ordering. The dominant sentence structure error was $7.15 \%$ with number 85 errors of omission in the adverbial and adverbial complement element of the simple sentence. A lot of error in the element of the sentence structure in writing application letter caused by the omission, selection, and addition of some letter in the element. The error also caused by the application of the capital letter, punctuation, and conjunction while the error of ordering was due to the sequence of the element in the sentence structure was incorrect placed

Regarding to the findings and discussions, there are some suggestion that can be derived in the field of students' error in sentence structure in writing application letter. For the student, related to the objective of the vocational school, the student should be more careful in writing application letter because it is important for them in applying a job. They should pay attention more in writing a sentence especially when they write a word and use a conjunction or punctuation. The word should be written completely. The conjunction and punctuation also should be used correctly. The student learns intensively the tense especially the using of the verb/auxiliary verb. It should be related to the form of tense to avoid the error of their using. For the teacher, the teacher should pay attention more in the writing subject teaching especially 
in making a sentence, using the suitable vocabulary, and the form of tense. The teacher should have any strategies and technique in teaching the students, in order to make the student understand about the lesson. The teacher should correct the paper assignment of the student directly, and explanation the error's, in order to avoid the errors happened again, and reduce the errors in the very beginning. For the school, the vocational school should help the English teacher for the English teaching and facilitate enough what the English lesson needs to improve the student capability in English especially in writing subject.

\section{REFERENCES}

Abushihab, Ibrahim. (2014). An analysis of grammatical errors in writing made by Turkhish learners of English as a foreign language. Vol.6, No.4. Published by International Journal of Linguistics, ISSN 1948-5425. Alzaytoonah University of Jordan, Jordan.

Al-Badawi, Khalid. (2012). An analysis of phonetic, morpohological and syntactic error in English: A case study of Saudi BA Students at King Khalid University. Vol.2, No.6. Published by International Journal of Social Science and Humanity, DOI: 10.7763/IJSSH.2012.V2.165. King Khalid University, Abha, and Kingdom of Saudi Arabia.

Alduais, Ahmed Mohammed Saleh. (2012). Simple sentence structure of standard arabic language and standard English language: A contrastive study. Vol.4, No.4. Published by International Journal of Linguistics, ISSN: 1948-5425. Department of English, King Saud University (KSU). Riyadh, Saudi Arabia.

Amara,Naimi. (2015). Errors correction in foreign language teaching. Published by The Online Journal of New Horizons in Education, Volume 5, Issue 3, Department of English, Hassiba Benbouali University. Chlef.

Dutwin, Phyllis.(2010). English grammar demystified a self-teaching guide. ISBN: 978-0-07160081-1. Published by The McGraw-Hill Companies, USA.

Erdogan, Vacide. (2005). Contribution of error analysis to foreign language teaching. Published Mersin University Journal of the Faculty of Education, Volume 1, Issue 2. Mersin University.

Fang, Xie \& Xue-mei. (2007). Error analysis and the EFL classroom teaching. Vol.4, No.9, Serial number 34. Published by US-China Education Review, ISSN: 1548-6613. USA.

Filed, Marion. (2009). Improve your written English "Master the essential of grammar, punctuation and spelling and write with greater confidence. Published by How to content, A division how to books Ltd, Oxford OX5 1RX. ISBN: 978-1-84803-330-6. United Kingdom.

Gelderen, Elly van (2010). An introduction to the grammar of English. Published by John Benjamins B.V. ISBN: 978-90-272-3270-0. Amsterdam/Philadelphia. 
Give, Lisa M. (2008). The sage encyclopedia of qualitative research methods. Volume $1 \& 2$. Published by Sage Publications, Inc. ISBN 978-4129-4163-1 (cloth). United Stated of America.

Greenbaum, Sidney., \& Gerald Nelson. (2002). An introduction to English grammar. Published by Person Education Limited. ISBN: 0-582-43741-5. Great Britain.

Maxom, Michelle. (2009). Teaching English as a foreign language for dummies. Published by John Wiley \& Sons, Ltd, ISBN: 978-0-470-74576-2. Chichester, West Sussex.England.

Widiati, Utami., Zuliati Rahmah., and Furaidah. (2015). Bahasa Inggris untuk kelas SMA/MA/SMK/MAK, cetakan ke-1. Published by Pusat Kurikulum dan Perbukuan, Balitbang, Kemdikbud, ISBN: 978-602-282-000-0. Jakarta.

Wilson, Kevin., \& Jennifer Wauson. (2010). The ama handbook of business writing. ISBN-13: 978-0-8144-1589-4. Published by Amacom. New York. 